\title{
The Application of Social Media in Education and Teaching in the Mobile Internet Era
}

\author{
Chunyan Wang \\ College of Business Administration, Jilin Engineering Normal University, Changchun, China
}

541012329@qq.com

Keywords: Social media; Education; Micro-blog; WeChat; Application

\begin{abstract}
With the popularity of mobile Internet, a variety of applications about mobile social media have emerged, and social media is gradually integrated into people's daily routine. Group of student is one of the easiest and most receptive groups to new things, who are the mainly users of social media, so the application of social media in education and teaching has been paid more attention by educators. With integrating social media into the process of teaching process, this study explores the impact of social media on educational and teaching activities through qualitative research and questionnaire survey methods, as well as the relationship between teachers and students.
\end{abstract}

\section{Introduction}

Social Media are computer-mediated technologies that allow the creating and sharing of information, ideas, career interests and other forms of expression via virtual communities and networks [1]. The emergence of the mobile Internet has promoted the social media to instant and mobile development. With the popularity of smart phones, tablet computers and mobile terminals, users can access any kind of information at any time. The faster the development of mobile Internet, the greater the impact of social media. With the rapid development of Internet Technology, mobile media bursts the amazing energy, and its dissemination of information has become an important part of people's browsing the Internet [2].

In recent years, with the rapid development and popularity of Internet technology, micro blogs, We Chat and other social media has gradually penetrated into all aspects of people's daily life and work. Especially in the special group of the post-90s college students, they generally prefer to pay attention to those of well-known scholars, journalists, entrepreneurs, and superstars by social media. To focus on them as the information source, they can update knowledge, access to information, share ideas, and establish individual circle of information and knowledge in line with their interests and needs [3]. According to Statistical Report on Internet Development in China (July 2016), "Up to June 2016, Chinese Internet users, 25.1\% were students" [4].Today, with the development of Internet, social media as a new social platform, has been favored by the majority of teachers and students. In spite of using the multimedia tools, the teachers still use the teaching method of speaking and the students relay on listening and noting as the main study method of learning in the traditional teaching of colleges and universities.

In the mobile Internet era, the status of university teachers as the center of knowledge dissemination has been further marginalized [5]. Teachers and students can use social media to conduct academic exploration, class management, resource sharing and a series of activities. Social media can not only be used as a dating platform, but also can become a good communication platform for teachers and students.

\section{Application of Social Media in Teaching}

In the professional teaching of tourism management courses, based on the characteristics of students and curriculums, undergraduate students and teachers are the subjects of this study with the course of "Tourism Aesthetics" and "Graduation Thesis Guidance" as curriculum practice object. Respectively 
using micro-blogs and We Chat as the teaching assistant platform, it carries out academic research, resources sharing, notice issued and other activities.

At first, in the Curriculum Teaching of "Tourism Aesthetics", this study uses micro-blogs as media platform. Micro-blog, which has the characteristics of micro content, fast and convenient operation and flexible communication at the same time, also supports images, audio, video and other multimedia content. Users are not only the creator of micro-blog's content, but also the disseminator of micro-blog content and sharing. The Teachers can post, reply, comment and forward information on micro-blog, can also use some functions such as micro-blog group, micro-blog wall to make more in-depth discussion, and then to overcome the limitation of time, place and students' psychological factors when they make a discussion between teachers and students in the traditional teaching. Using micro-blog to launch education and teaching activities, it not only can stimulate students' interest in learning, but also can create active classroom atmosphere. Micro-blog to make learning activities is no longer monotonous infusion, but a new situation of brainstorming and collaborative learning, so as to completely stimulate the enthusiasm of students learning.

In the teaching links of "Graduation Thesis Guidance", the social platform of We Chat is used in this research. During the process of guiding the graduation thesis, most of the students are involved in the practice, so it is difficult for a teacher to do the work of graduation thesis guidance as normal teaching by face-to-face. As a social media, We Chat is just to provide a convenient link for teachers and students during the teaching process. We Chat's biggest feature is to support the transmission of voice information, video images and text, and also to support more people to talk at same time, which is very favorable to checking, answering, noticing during the guiding their graduation thesis.

\section{Application of Micro-blog in the Teaching Process}

This study takes the micro-blog application in the course of "Tourism Aesthetics" as an example, and carries out a retrospective study on it, and explores the problem from the perspective of both teachers and students.

According to the requirements of qualitative research [6], it summarizes all the contents of the teacher's micro-blog during the course, including the release of teachers, the comments of students and the reply of teachers and so on, which issued on the micro-blog; then these contents are transcribed into related documents, excluding the conversations and comments from outside personnel, removing a small amount of meaningless emoticons and comments which are not related to learning; finally, the content of micro-blog form teachers and students are classified, on the basis of analysis and comparison. Among them, the content of micro-blog from teachers is divided into three categories, namely, academic content, emotional content and others. The content from students is a total of four categories, namely academic content, cognitive content, emotional content, learning motivation and others. The content of students' academic learning refers to the content of curriculum; the cognitive content refers to the understanding of knowledge, and thinking of learning activities; the emotional content refers to the greetings and attentions conveyed from students to teachers; learning motivation refers to the driving force to promote the learning activities; the others refer to the chat from students.

Through the analysis of interactive content, type and frequency of micro-blogs, it can be seen that the teacher provides academic and emotional supports to students through academic and emotional content in the process of teaching interaction between teacher and students by micro-blog.

When teachers respond to students' comments, whether answering, correcting, or chatting in response, the reply will be used to forward, which is conducive to make the students to see the process of answering, modifying or chatting clearly, to show the process of applying knowledge to other students. In the whole teaching process, teachers and students interact frequently that effectively stimulates students' learning enthusiasm and learning motivation. At the same time, academic, cognitive and emotional content from students also shows that teachers give attention to students' learning activities from the cognitive, emotional and other aspects, and social media has played a role in promoting the construction of close and friendly relationship between teachers and students. 


\section{Investigation and Analysis}

In order to better understand the application of social media in teaching, this study also uses the questionnaire survey to master and evaluate the use of social media between teachers and students, and found that the use of social media skills, etc.. This study will survey "social media in the teaching application survey" published on www.sojump.com. Then invited the students who have taken the course of "Tourism Aesthetics" to complete this online questionnaire, a total of 131 valid questionnaires were returned (including 99 girls, 32 boys).

Analysis of Social Media's Applications. Through this questionnaire survey found that almost all of the students use micro-blog, We chat and other social media, and the use of social media for a variety of purposes, but the main purpose is to chat, make friends and so on. The proportion of students who use social media to study is very few, accounting for only $43.53 \%$. The specific proportion is shown in Fig. 1

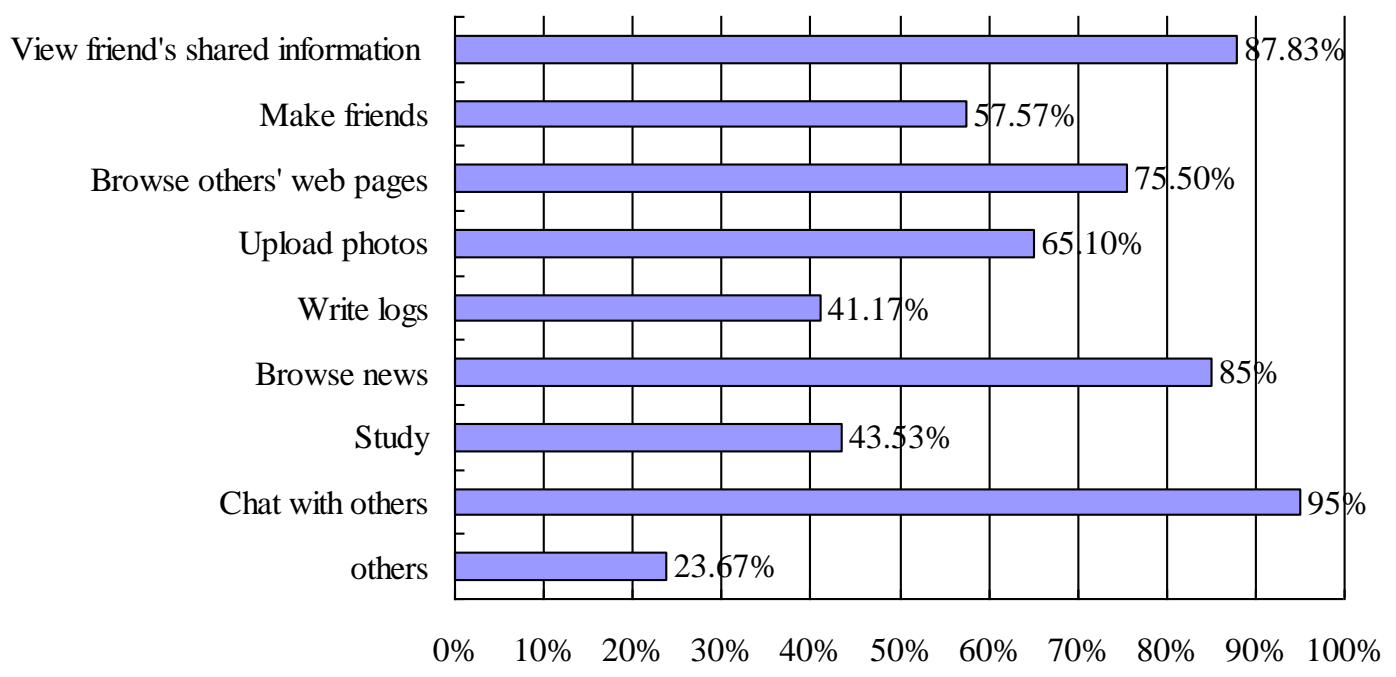

Figure 1. Applications of social media for students

The survey found that the proportion of students using social media to interact with teachers is not high, its proportion of "always be using" accounts for $23.33 \%$. The proportion of teachers using social media to interact with students is higher, "frequently used" accounting for $33.43 \%$. When using social media for interactive learning, compared to interact with teachers, students are more willing to interact with the students and the knowledge itself, its proportion is as high as $65 \%$ and $20.83 \%$ respectively, but the proportion of interacting with teachers is only $8.33 \%$.

The results show that most of students like chatting on social media instead of learning. Even learning or acquiring knowledge by social media, they prefer to trust the opinion leaders or friends rather than ask teachers, which make the teacher's position more and more marginalized in the spread of knowledge. In the future, how to use social media properly and play its role in teaching is worth exploring ${ }^{[7]}$.

Analysis of the Acceptance of Social Media in Teaching. In the survey of "students are interested in teachers' teaching by using social media or not", the proportion of positive attitude is $94.17 \%$, negative only for $5.83 \%$. About "If social media is used in teaching, whether you prefer to use this way to interact with objects or not", it results show that "very pleasant" accounted for $\mathrm{t} 40.3 \%$. The question of "Whether you are willing to participate, concern, forward or reply", its proportion of positive attitude is as high as $80.53 \%$. "If teachers use social media to set up a learning group, whether you are willing to participate in and discuss with others", the proportion of it is $86.67 \%$.

These data show that the majority of students are willing to interact with teachers through social media. It can be seen that social media has its advantages in teaching, so it is imperative that social media can promote teaching and learning program.

Analysis of the Reasons of Using Social Media for Teaching and Learning. How to effectively use the social media to assist teaching, stimulate the enthusiasm of students to learn, to build a good 
relationship between teachers and students is worth exploring ${ }^{[8]}$. Through the questionnaire survey, it can get the various reasons why students use social media to interact with teachers, including regional limitation, teacher's reason, personal preference, introverted personality and others. The regional limitation is the main reason for using the social media in teaching and learning. As shown in Fig. 2.

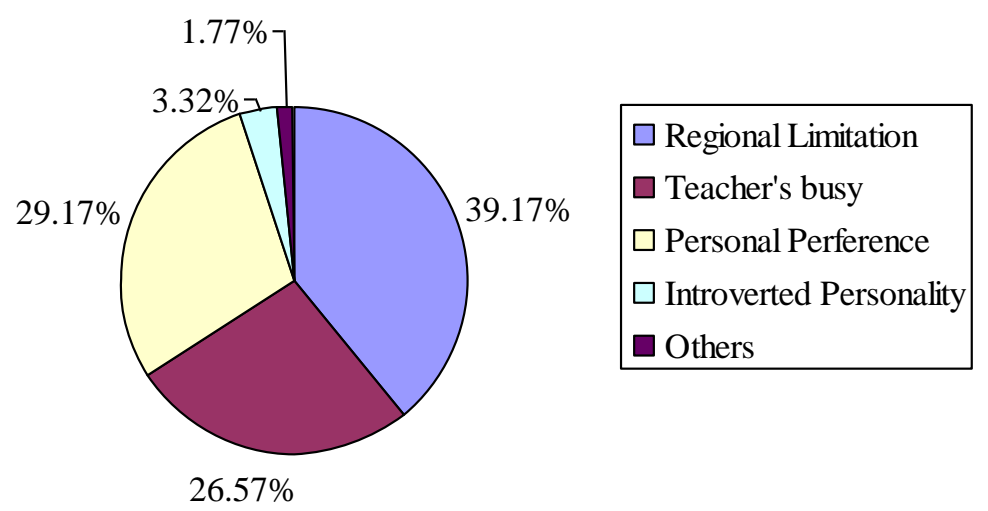

Figure 2. Reasons of using social media for Teaching and Learning

In the teaching process by using social media, students are more willing to forward, and its proportion is as high as $55.83 \%$, followed by the comments, accounted for $26.67 \%$, next is a private letter, accounting for $8.33 \%$. The result of "If building a special learning social networking site, what the function the students want to?" shows that students want to use the function followed by instant chatting, sharing, uploading, making friends, leaving message and others. The investigation on "in which courses you hope teachers to use social media" shows that students mostly hope to use social media to communicate with the teacher in the teaching process of graduation design, professional courses and training courses.

From the above analyses, it can been seen that the use of social media in teaching has the following advantages: firstly, it expands the teaching space from the classroom to the outside of the classroom in the university, and makes the scattered time effectively; secondly, it realizes the mobile learning by $4 \mathrm{G}$ network and mobile devices, and builds a virtual learning environment; finally, it improves the feedback efficiency of learning, understands the effect of students' learning by observing the exchange of students in micro-blog and improves the teaching methods in a timely manner.

\section{Conclusions}

Teachers can provide academic support and emotional support for students by using social media to communicate with students, to stimulate students' learning motivation, make up for the limitations of traditional classroom teaching, and promote student's autonomous learning and collaborative learning ability. But social media has a limited direct effect on the course of learning, because it's not a lot of direct content in social media that involves curriculum. Therefore, if we want to play the greatest value of social media in teaching, still need to continue to try and practice [9].

Through the application, the qualitative research, the practical investigation and analysis, it can be known that the education and teaching activities by social media have many advantages compared with the traditional education and teaching activities. The education and teaching activities, which are integrated into the social media, are more flexible and convenient, that can stimulate students' interest in learning, promote collaborative learning, and cultivate teamwork spirit. Teachers can freely express feelings, ideas, teaching reflection, experiences exchange and so on in social media [10]. At the same time, there are a variety of drawbacks in this kind of teaching activities. For some students who lack self-control and discrimination, the teaching activities by using social media will be more difficult to control, that need teachers to guide students properly and supervise the whole process of teaching in social media. If we can overcome these disadvantages and difficulties, social media will bring more benefits to teaching. 


\section{Acknowledgements}

This work was financially supported by Education and Teaching Research Project of Jilin Engineering Normal University.

\section{References}

[1] J. A. Obar, W. Steve: Annals of the Telecommunications Policy, Vol. 39 (2015) No.9, p.745-750.

[2] T.Y. Liu, Q.H. Meng: Annals of China Educational Technology and Equipment, Vol. 19 (2012) No.15, p.138-139.

[3] W. Zhu: Journal of Anyang Normal University, Vol. 14 (2012) No.2, p.137-139.

[4] Information on http://cnnic.com.cn

[5] H.W. Xie: Annals of Press Outpost, Vol. 21 (2012) No.4, p.31-33.

[6] X.M. Chen: Qualitative Research in Social Sciences (Educational Science Publishing House, China 2000).

[7] L.J. Zhang, L.H. Xu: Annals of Software Guide, Vol. 14 (2015) No.4, p.158-159.

[8] R.B. Wang, C.T. Du and B.B. Zhang: Annals of China Educational Technology, Vol. 22 (2015) No.4, p.113-119.

[9] Y.W. Wang, S.Y. Gong and J.W. Li: Annals of Teacher Education Forum, Vol. 27 (2014) No.1, p.83-89.

[10] L. Ni: Annals of Youth Journalist, Vol. 20 (2013) No.1, p.83-89. 